\title{
Intramucosal lipomas of the colon implicate Cowden syndrome
}

\author{
Aybuke Caliskan ${ }^{1}$, Wendy K Kohlmann², Kajsa E Affolter ${ }^{3}$, Erinn Downs-Kelly ${ }^{4}$, \\ Priyanka Kanth ${ }^{5}$ and Mary P Bronner ${ }^{3}$ \\ ${ }^{1}$ Acibadem University School of Medicine, Istanbul, Turkey; ${ }^{2}$ Department of Genetics Counselors, Huntsman \\ Cancer Institute, University of Utah Health Sciences Center, Salt Lake City, UT, USA; ${ }^{3}$ Department of \\ Pathology and ARUP Laboratories, University of Utah Health Sciences Center, Salt Lake City, UT, USA; \\ ${ }^{4}$ Department of Pathology and Laboratory Medicine, Cleveland Clinic Foundation, Cleveland, OH, USA and \\ ${ }^{5}$ Division of Gastroenterology University of Utah Health Sciences Center, Salt Lake City, UT, USA
}

\begin{abstract}
Intramucosal lipomas are rare and easily overlooked by pathologists, despite their diagnostic significance for Cowden syndrome (PTEN hamartoma tumor syndrome), an inherited multiorgan cancer syndrome. Only 25-35\% of patients harbor identifiable PTEN mutations, thus clinical features, like intramucosal lipomas, remain the mainstay of diagnosis. The significance and diagnostic approach to intramucosal lipomas have not been thoroughly addressed in the literature. Intramucosal lipomas are mimicked by pseudolipomatosis coli, an artifactual mucosal gas infiltration from endoscopic insufflation. This differential was investigated by morphology and S-100 immunohistochemistry. Twenty-five colonic intramucosal lipomas were identified from 176 archival gastrointestinal lipomas from 1998 to 2017. Controls included 40 submucosal lipomas and 30 pseudolipomatoses. S-100 immunohistochemistry on all 95 lesions confirmed delicate fat vacuole membranous and nuclear S-100 staining in lipomas absent from pseudolipomatoses. Differentiating morphology between intramucosal lipoma and pseudolipomatosis, respectively, included consistently large, regular fat vacuoles (92\% vs $7 \%$ ), associated spindle cells ( $80 \%$ vs $0 \%$ ), and mucosal lymphoid aggregate involvement (12\% vs $80 \%)$. Of the 25 intramucosal lipomas, five patients (20\%) had confirmed Cowden syndrome (four with PTEN mutations). In four of these Cowden patients, the intramucosal lipoma was the index diagnostic lesion. Three (12\%) intramucosal lipoma patients had additional clinical features associated with Cowden syndrome, but did not meet the diagnostic criteria. Sporadic-type intramucosal lipomas were identified in 17 patients (68\%) without evidence of Cowden syndrome, including three with normal PTEN genetic testing. No distinguishing endoscopic or pathologic polyp features were identified between sporadic and syndromic intramucosal lipomas. These data provide evidence that intramucosal lipomas are important harbingers of Cowden syndrome, making up approximately one-third of this series, the largest in the literature. We also show for the first time that two-thirds of intramucosal lipomas are sporadic. Gastrointestinal pathologists, gastroenterologists, and geneticists should increase their awareness of this subtle but diagnosable lesion strongly associated with Cowden syndrome. Modern Pathology (2018) 31, 643-651; doi:10.1038/modpathol.2017.161; published online 1 December 2017
\end{abstract}

Gastrointestinal tract lipomas are not uncommon, most frequently occur in the colon, and are submucosal in the great majority. ${ }^{1}$ Intramucosal lipomas, in contrast, are rare and have not been described outside Cowden syndrome. The possibility that they could represent incidental sporadic

Correspondence: Dr MP Bronner, MD, Department of Pathology and ARUP Laboratories, Huntsman Cancer Institute, University of Utah, Room N3100, 1950 Circle of Hope, Salt Lake City, UT 84112, USA.

E-mail: mary.bronner@aruplab.com

Received 2 September 2017; revised 26 September 2017; accepted 14 October 2017; published online 1 December 2017 lesions has not been explored. Morphologically, they are mimicked by infiltration of gas into the mucosa from luminal air insufflation during colonoscopy, a phenomenon that has been termed pseudolipomatosis. This series investigates the diagnostic utility of intramucosal lipomas for Cowden syndrome and how to distinguish them from their mimic, pseudolipomatosis, ${ }^{2,3}$ by morphology and S-100 immunohistochemical staining.

The aim of this study was to assess the sensitivity and specificity and diagnostic approaches to gastrointestinal intramucosal lipomas for Cowden syndrome in comparison with pertinent controls, in this the largest reported series in the literature. We seek 
to raise the awareness of gastrointestinal pathologists, gastroenterologists, and clinical geneticists for this lesion, the intramucosal lipoma, and thereby improve the diagnosis of Cowden syndrome, an important inherited and high-risk multicancer syndrome.

\section{Materials and methods}

\section{Patients}

This study was approved by the University of Utah's institutional review board. The pathology archives were searched for any type of gastrointestinal lipoma from 1998 to 2017. Of the 176 identified gastrointestinal lipomas of any type, a total of 25 were histologically confirmed to have intramucosal fat. These patients were further investigated by the Genetics Counseling Department of the Huntsman Cancer Institute at the University of Utah, to identify those patients with confirmed diagnoses of Cowden syndrome, either by identifying deleterious PTEN genetic mutations and/or clinical features (Table 1). Germline PTEN mutation testing was performed with informed patient consent, and detailed family and past medical histories and physical examinations were conducted for Cowden syndrome evaluation by the Genetics Counseling Department. Two control groups consisted of 40 patients with submucosal lipomas and 30 with pseudolipomatosis coli.

\section{Pathology}

The archival histologic slides of all cases and controls were obtained and reviewed systematically by experienced gastrointestinal pathologists. To distinguish true intramucosal lipomas from pseudolipomatosis, morphologic features were compared and routine S-100 immunohistochemical staining was performed. The morphologic features evaluated included the (1) size and regularity of the lesional open spaces/holes, were they gas in pseudolipomatosis or lipid in lipomas, (2) the location of the lesions within the mucosa, (3) their relationship to colonic crypts and mucosal-associated lymphoid aggregates, (4) whether submucosal lipomas ever breached the muscularis mucosae to enter the overlying lamina propria, and (5) associated lamina propria spindle cell mesenchymal proliferations. S-100 immunohistochemical staining patterns were assessed for either (1) total non-staining of lesional holes in pseudolipomatosis, (2) staining of scattered non-lesional lamina propria dentritic cells with definable delicate dentritic processes, or (3) delicate membranous cytoplasmic rim staining around true lipid vacuoles in lipomas plus/minus nuclear staining of the small adipocyte nuclei within plane of sectioning.
Table 1 Consensus clinical diagnostic criteria for CS

Major criteria

Breast cancer

- Epithelial thyroid cancer (follicular)

- Macrocephaly (occipital frontal circumference $\geq 97$ th percentile)

- Endometrial carcinoma

- Gastrointestinal hamartomas $\geq$ (including ganglioneuromas, but excluding hyperplastic polyps)

- Lhermite-Duclos disease (adult)

- Macular pigmentation of the glans penis

- Multiple cutaneous lesions (any of the following):

○ Multiple trichilemmomas $(\geq 3$, at least one biopsy proven)

- Acral keratosis ( $\geq 3$ palmoplantar keratotic pits and/or acral hyperkeratotic papules)

- Mucocutaneous neuromas $(\geq 3)$

- Oral papilloma (particularly on tongue and gingiva), multiple $(\geq 3)$

Minor criteria

- Autism spectrum disorder

- Colon cancer

- Esophageal glycogenic acanthosis $(\geq 3)$

- Lipomas $(>3)$

- Intellectual disability (IQ $\leq 75$ )

- Renal cell carcinoma

- Testicular lipomatosis

- Thyroid cancer (papillary or follicular variant)

- Thyroid structural lesion (eg, adenoma, multinodular goiter)

- Vascular abnormalities

An operational diagnosis of CS is made if an individual meets any one of the following criteria:

- Three or more major criteria, but one must include macrocephaly, Lhermite-Duclos disease, or gastrointestinal hamartomas.

- Two major and three minor criteria

In a family in which one individual meets the diagnostic criteria for CS listed above, other relatives are considered to have a diagnosis of CS if they meet any one of the following criteria:

- Any two major criteria

- One major and two minor criteria

- Three minor criteria

Abbreviations: $\mathrm{CS}=$ Cowden syndrome; IQ = intelligence quotient.

Genetic germline PTEN testing was performed through sequencing of all exons and adjacent introns. In the absence of mutations, additional large rearrangement testing was performed. In the case of a known mutation in one family, site-specific PTEN testing for the familial mutation was undertaken.

\section{Results}

\section{Intramucosal Lipoma Patients}

Of the 25 intramucosal patients (Table 2), 20 were referred by their gastroenterologists for genetic counseling and nine of these patients subsequently underwent PTEN germline genetics testing based on genetic counseling recommendations and patient consent. Five patients met clinical diagnostic criteria for Cowden syndrome, and four of these five had 
Table 2 Clinicopathologic characteristics of sporadic and Cowden syndromic intramucosal lipomas

\begin{tabular}{|c|c|c|c|c|c|c|c|c|c|c|c|c|}
\hline \multirow{2}{*}{$\begin{array}{l}\text { Cowden } \\
\text { syndrome } \\
\text { diagnosis }\end{array}$} & \multirow{2}{*}{ Sex/age } & \multicolumn{4}{|c|}{ Intramucosal lipoma pathology } & \multirow{2}{*}{ Other colonic polyps } & \multirow{2}{*}{$\begin{array}{l}\text { PTEN } \\
\text { genetic } \\
\text { testing }\end{array}$} & \multirow{2}{*}{ Cancers } & \multirow{2}{*}{$\begin{array}{l}\text { Head circum- } \\
\text { ference }\end{array}$} & \multirow{2}{*}{$\begin{array}{l}\text { Skin } \\
\text { papules }\end{array}$} & \multirow{2}{*}{ Thyroid disease } & \multirow{2}{*}{$\begin{array}{l}\text { Develop- } \\
\text { mental } \\
\text { delay }\end{array}$} \\
\hline & & $\begin{array}{l}\text { S-100 } \\
\text { lipoma } \\
\text { staining } \\
\text { by IHC }\end{array}$ & $\begin{array}{l}\text { Stromal } \\
\text { spindle } \\
\text { cells }\end{array}$ & $\begin{array}{l}\text { Lamina } \\
\text { propria } \\
\text { limited } \\
\text { adipocytes }\end{array}$ & $\begin{array}{c}\text { Mucosal } \\
\text { lymphoid } \\
\text { tissue } \\
\text { involvement }\end{array}$ & & & & & & & \\
\hline \multicolumn{13}{|c|}{ Intramucosal lipomas in Cowden syndrome patients $(\mathrm{n}=5)$} \\
\hline $\mathrm{Y}$ & $\mathrm{F} / 25$ & $\mathrm{Y}$ & $\mathrm{Y}$ & $\mathrm{Y}$ & $\mathrm{N}$ & $\begin{array}{l}\text { Multiple } \\
\text { ganglioneuromas, } \\
\text { lymphoid polyps, } \\
\text { duodenal adenomas, } \\
\text { inflammatory polyps }\end{array}$ & $\begin{array}{l}\text { Deleterious } \\
\text { PTEN } \\
\text { mutation }\end{array}$ & $\begin{array}{l}\text { Endometrial } \\
\text { carcinoma }\end{array}$ & NT & $\mathrm{N}$ & $\begin{array}{l}\text { Multiple } \\
\text { thyroid nodules }\end{array}$ & $\mathrm{N}$ \\
\hline $\mathrm{Y}$ & $\mathrm{F} / 45$ & $\mathrm{Y}$ & $\mathrm{Y}$ & $\mathrm{Y}$ & $\mathrm{N}$ & ganglioneuroma & WT & $\begin{array}{l}\text { Thyroid } \\
\text { papillary } \\
\text { carcinoma }\end{array}$ & NT & $\mathrm{N}$ & $\mathrm{N}$ & $\mathrm{N}$ \\
\hline $\mathrm{Y}$ & $\mathrm{F} / 57$ & $\mathrm{Y}$ & $\mathrm{Y}$ & $\mathrm{Y}$ & $\mathrm{N}$ & $\begin{array}{l}\text { Sessile serrated polyp, } \\
\text { lymphoid polyp, } \\
\text { inflammatory polyps, } \\
\text { hyperplastic polyp }\end{array}$ & $\begin{array}{l}\text { Deleterious } \\
\text { PTEN } \\
\text { mutation }\end{array}$ & $\begin{array}{l}\text { Endometrial } \\
\text { carcinoma }\end{array}$ & Macrocephaly & $\mathrm{N}$ & Thyroid goiter & $\begin{array}{l}\text { Mental } \\
\text { health } \\
\text { disorder }\end{array}$ \\
\hline $\mathrm{Y}$ & $\mathrm{M} / 51$ & $\mathrm{Y}$ & $\mathrm{Y}$ & $\mathrm{Y}$ & $\mathrm{N}$ & $\begin{array}{l}\text { Adenomas, hyperplastic } \\
\text { polyp, inflammatory } \\
\text { polyps }\end{array}$ & $\begin{array}{l}\text { Deleterious } \\
\text { PTEN } \\
\text { mutation }\end{array}$ & Melanoma & Normal & $\mathrm{N}$ & $\begin{array}{l}\text { Thyroid } \\
\text { nodules }\end{array}$ & $\mathrm{N}$ \\
\hline $\mathrm{Y}$ & $\mathrm{M} / 41$ & $\mathrm{Y}$ & $\mathrm{Y}$ & $\mathrm{Y}$ & $\mathrm{N}$ & $\begin{array}{l}\text { Diffuse colonic } \\
\text { polyposis, adenomas, } \\
\text { inflammatory, } \\
\text { ganglioneuromatous, } \\
\text { hyperplastic and } \\
\text { lymphoid polyps }\end{array}$ & $\begin{array}{l}\text { Deleterious } \\
\text { PTEN } \\
\text { mutation }\end{array}$ & $\mathrm{N}$ & Macrocephaly & & $\begin{array}{l}\text { Goiter, } \\
\text { thyroidectomy } \\
\text { age } 28 \text { years }\end{array}$ & $\mathrm{N}$ \\
\hline \multicolumn{13}{|c|}{ Intramucosal lipomas in possible Cowden syndrome patients not meeting full diagnostic criteria $(\mathrm{n}=3)$} \\
\hline Possible & $\mathrm{M} / 30$ & $\mathrm{Y}$ & $\mathrm{Y}$ & Y & $\mathrm{Y}$ & $\begin{array}{l}\text { Adenoma, hyperplastic } \\
\text { polyp, sessile serrated } \\
\text { polyp ganglioneuroma }\end{array}$ & $\begin{array}{l}\text { WT (VUS in } \\
\text { APC) }\end{array}$ & $\mathrm{N}$ & Macrocephaly & $\begin{array}{l}\text { Tongue } \\
\text { papule }\end{array}$ & $\mathrm{N}$ & $\mathrm{Y}$ \\
\hline Possible & $\mathrm{M} / 51$ & $\mathrm{Y}$ & $\mathrm{Y}$ & $\mathrm{Y}$ & $\mathrm{N}$ & Adenomas & NT & $\mathrm{N}$ & NT & $\mathrm{N}$ & $\mathrm{N}$ & $\mathrm{N}$ \\
\hline Possible & $\mathrm{M} / 61$ & $\mathrm{Y}$ & $\mathrm{Y}$ & $\mathrm{Y}$ & $\mathrm{N}$ & & NT & $\mathrm{N}$ & NT & & $\begin{array}{l}\text { Thyroid } \\
\text { nodules }\end{array}$ & $\mathrm{N}$ \\
\hline \multicolumn{13}{|c|}{ Sporadic intramucosal lipomas patients without clinical or genetic features of Cowden syndrome $(\mathrm{n}=17)$} \\
\hline $\mathrm{N}$ & $\mathrm{F} / 29$ & $\mathrm{Y}$ & $\mathrm{N}$ & $\mathrm{Y}$ & $\mathrm{Y}$ & Hyperplastic polyps & NT & $\mathrm{N}$ & Normal & $\mathrm{N}$ & $\mathrm{N}$ & $\mathrm{N}$ \\
\hline $\mathrm{N}$ & $\mathrm{F} / 79$ & $\mathrm{Y}$ & $\mathrm{N}$ & $\mathrm{Y}$ & $\mathrm{Y}$ & Adenomas & NT & $\mathrm{N}$ & Normal & $\mathrm{N}$ & $\mathrm{N}$ & $\mathrm{N}$ \\
\hline $\mathrm{N}$ & $\mathrm{M} / 43$ & $\mathrm{Y}$ & $\mathrm{N}$ & Y & $\mathrm{N}$ & None & NT & $\mathrm{N}$ & NT & $\mathrm{Y}$ & $\mathrm{N}$ & $\mathrm{N}$ \\
\hline $\mathrm{N}$ & $\mathrm{F} / 75$ & $\mathrm{Y}$ & $\mathrm{N}$ & $\mathrm{Y}$ & $\mathrm{N}$ & Fundic gland polyps & NT & $\mathrm{N}$ & Normal & $\mathrm{N}$ & $\mathrm{N}$ & $\mathrm{N}$ \\
\hline $\mathrm{N}$ & $\mathrm{F} / 67$ & Y & $\mathrm{N}$ & $\mathrm{Y}$ & $\mathrm{N}$ & Adenoma & NT & $\begin{array}{l}\text { Melanoma, } \\
\text { BCC, SCC }\end{array}$ & NT & $\mathrm{Y}$ & $\mathrm{N}$ & $\mathrm{N}$ \\
\hline $\mathrm{N}$ & $\mathrm{F} / 53$ & Y & Y & Y & $\mathrm{N}$ & $\begin{array}{l}\text { Adenoma, hyperplastic } \\
\text { polyp }\end{array}$ & NT & $\mathrm{N}$ & NT & $\mathrm{N}$ & $\mathrm{N}$ & $\mathrm{N}$ \\
\hline $\mathrm{N}$ & $\mathrm{M} / 50$ & $\mathrm{Y}$ & $\mathrm{Y}$ & $\mathrm{Y}$ & $\mathrm{N}$ & Adenomas & NT & $\mathrm{N}$ & NT & $\mathrm{N}$ & $\mathrm{N}$ & $\mathrm{N}$ \\
\hline $\mathrm{N}$ & $\mathrm{F} / 54$ & $\mathrm{Y}$ & $\mathrm{Y}$ & $\mathrm{Y}$ & $\mathrm{N}$ & $\begin{array}{l}\text { Adenomas, sessile } \\
\text { serrated polyp }\end{array}$ & WT & $\mathrm{N}$ & $\begin{array}{l}\text { Macro- } \\
\text { cephaly }\end{array}$ & $\mathrm{N}$ & $\mathrm{N}$ & $\mathrm{N}$ \\
\hline
\end{tabular}


pathogenic variants in the PTEN gene. Of the five confirmed Cowden syndrome patients, one had papillary thyroid carcinoma, two had endometrial adenocarcinoma, and one had melanoma. The average age of diagnosis of the Cowden syndrome patients was 44 years (range 25-57 years) with three females and two males (Table 2).

While all Cowden patients had multiple features warranting clinical genetics referral, detection of their intramucosal lipoma was the feature that prompted evaluation for Cowden syndrome in four of the five confirmed patients, validating the significant potential of this lesion for diagnosing Cowden syndrome. Three patients $(12 \%)$ had some additional features of Cowden syndrome, but did not meet the clinical or genetic diagnostic criteria. One had macrocephaly and tongue papules, but genetic testing of PTEN did not disclose a pathogenic mutation. The other two each presented with either a single ganglioneuroma or thyroid nodules, and no genetic testing was performed (Table 2).

Finally, 17 patients (68\%) had no additional features associated with Cowden syndrome. PTEN genetic testing was pursued in three of these patients that did not disclose pathogenic variants. These $68 \%$ of intramucosal lipomas in this series then document the first reported sporadic-type intramucosal lipomas in the literature, unrelated to Cowden syndrome (Table 2).

\section{Endoscopy}

On colonoscopic examination, the five Cowden syndrome patients had multiple polyps, ranging anywhere from 30 to more than a 100 polyps. The multiple polyp types were mostly sessile and between 1 and $10 \mathrm{~mm}$ in size. The intramucosal lipomas were all colonic and small, ranging from 3 to $5 \mathrm{~mm}$ in size, and appeared endoscopically similar to that of hyperplastic, hamartomatous, or

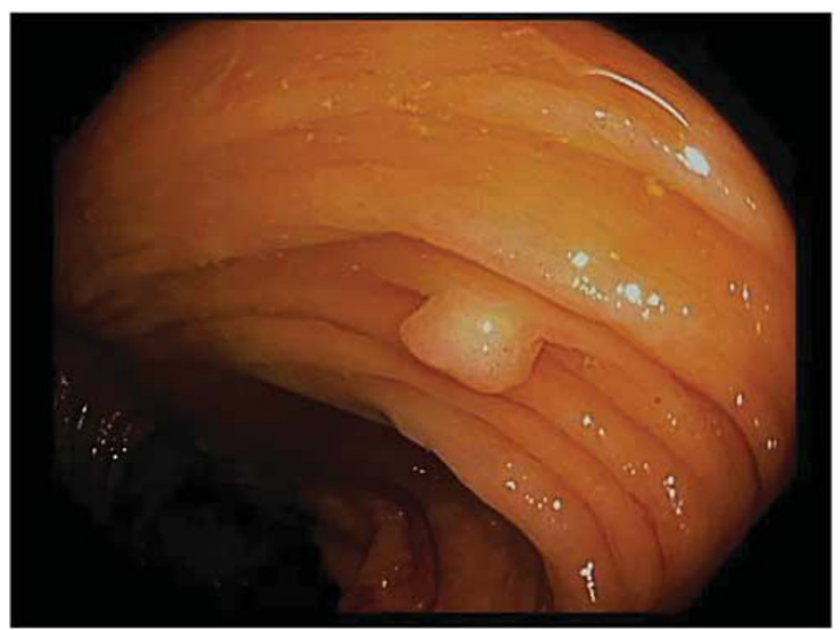

Figure 1 Endoscopic image of a small $3 \mathrm{~mm}$ colonic and syndromic intramucosal lipoma from a Cowden patient. No specific distinguishing endoscopic features are present. 
adenomatous polyps (Figure 1). Thus, no specific distinguishing endoscopic features were noted for the intramucosal lipomas. The endoscopic appearance of the intramucosal lipomas did not, however, have the classic features of submucosal lipomas, which usually exhibit smooth surfaces with a "pillow sign' on compression, and often a yellowish polyp discoloration.

\section{Intramucosal Lipoma Histology}

Adipose tissue in the true intramucosal lipomas was more often present at the basal aspect of the lamina propria, adjacent to and surrounding colonic crypts, and most often (92\%) revealed large, fairly regular macrovesicular lipid vacuoles that were $>100 \mu \mathrm{m}$ or more in size (Figure 2a). The submucosal lipoma controls were all located entirely below the muscularis mucosae with no extension into the mucosa (Figure 2b). The adipocytes of the true intramucosal lipomas characteristically (76\%) lacked involvement of mucosal-associated lymphoid aggregates
(Figure 2a), unlike the majority $(80 \%)$ of pseudolipomatosis cases that did involve mucosal lymphoid tissue (Figures 2c and d). Some degree of benign spindle cell proliferation within the lamina propria was evident in 20 of $25(80 \%)$ of the intramucosal lipomas (Figures 3a and b,Table 2), while none of the submucosal lipoma (Figure $2 \mathrm{~b}$ ) or pseudolipomatosis controls (Figures 2c and d) showed this distinctive feature. The exact cell type comprising the spindle cell proliferation was not further pursued by immunohistochemistry, other than they were not S-100 positive after staining of all cases and controls. The spindle cells were all hypocellular, not mitotically active, and not cytologically atypical (Figures 3a and b), precluding the utility of further subtyping. Spindle cell proliferations were seen in all clinical categories of intramucosal lipomas, including Cowden syndrome patients, patients with suspicion for Cowden syndrome, and patients with sporadic lesions with no other clinical or genetic features of Cowden syndrome. Accordingly, the spindle cells were not helpful in differentiating these clinical

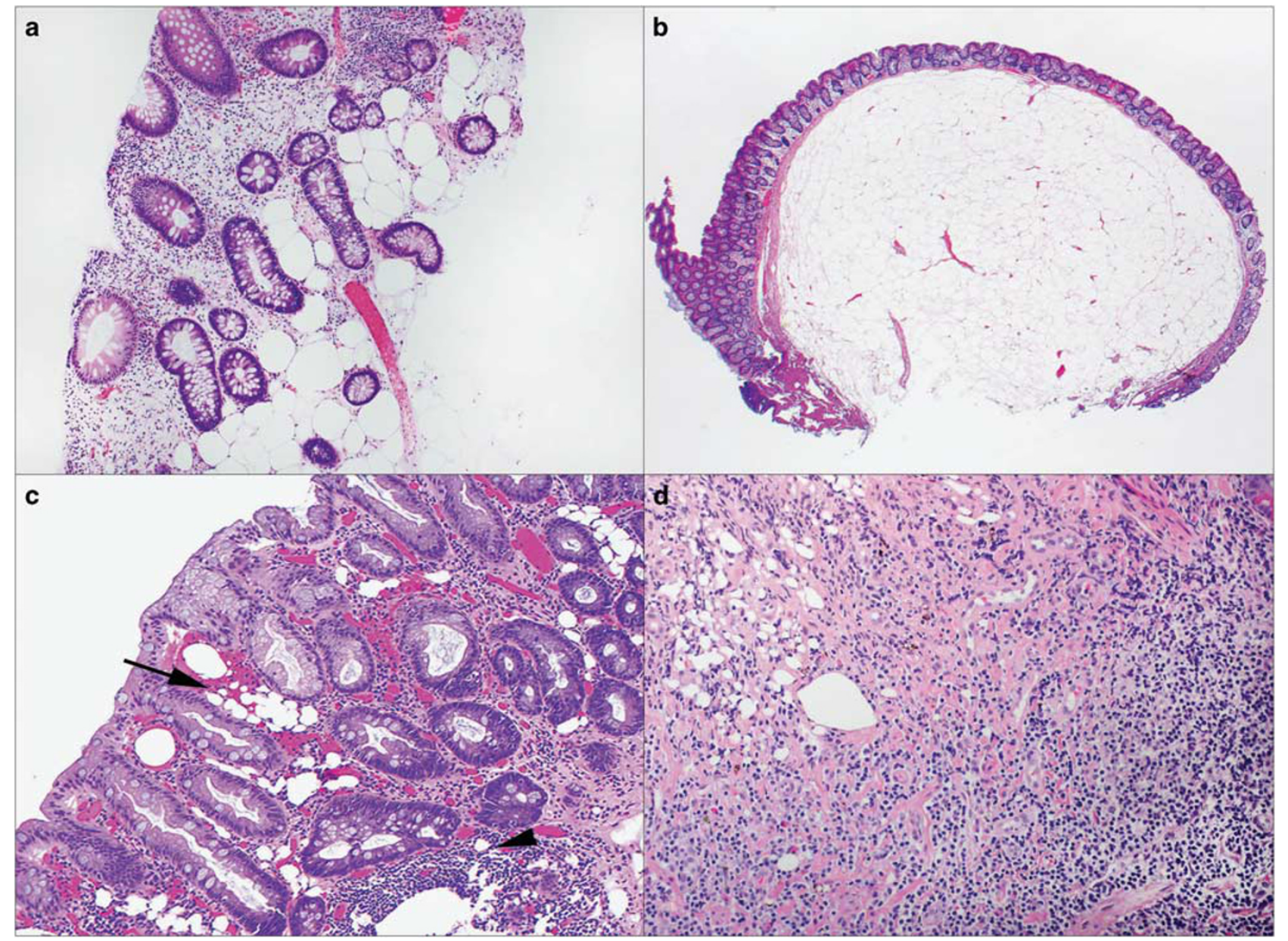

Figure 2 (a) Intramucosal lipoma $(\times 200)$, located at the basal aspect of the lamina propria, adjacent to and surrounding colonic crypts, and containing regularly sized macrovesicular lipid vacuoles. (b) Submucosal lipoma $(\times 40)$, located deep to the muscularis mucosae with no extension of adipocytes into the mucosa. (c) Pseudolipomatosis coli $(\times 200)$, with largely small and irregular holes (arrow) and involvement of lymphoid tissue (arrowhead). (d) Pseudolipomatosis coli $(\times 400)$, involving mucosal-associated lymphoid tissue. 


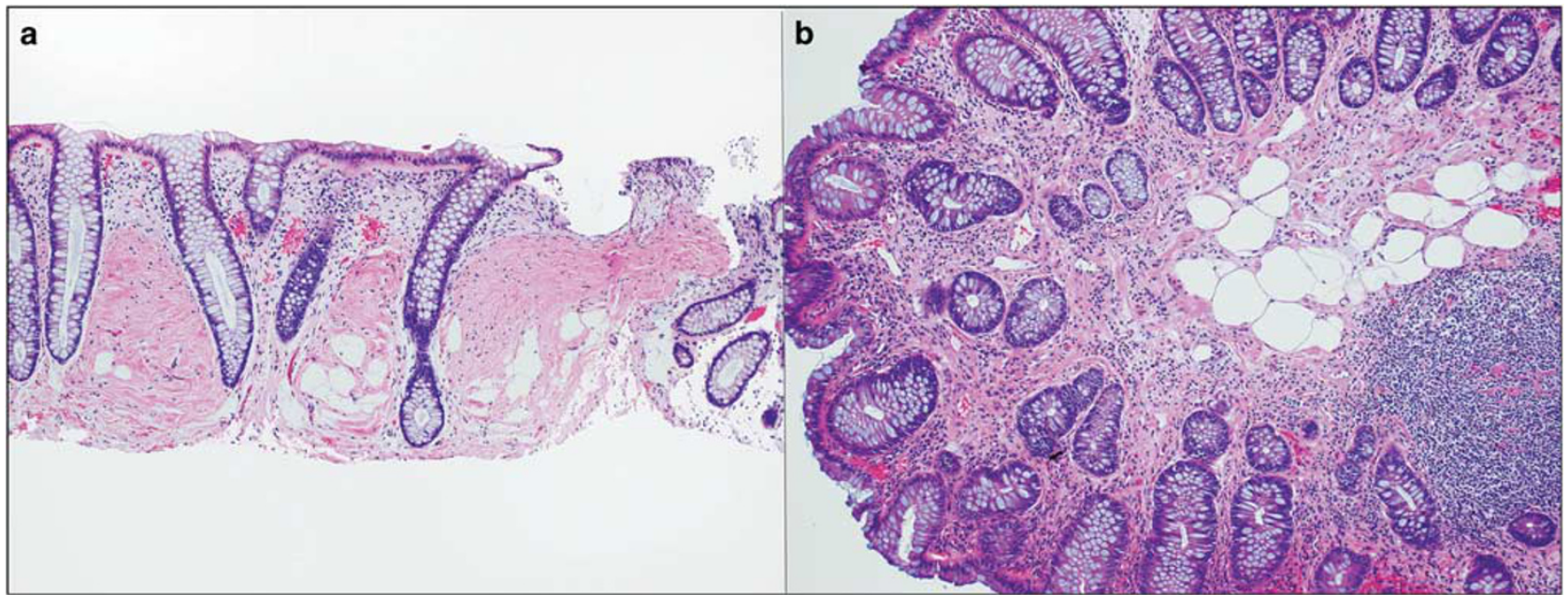

Figure 3 Spindle cell proliferations characteristic of $80 \%$ of true intramucosal lipomas and absent from all pseudolipomatosis coli in this series. (a) Prominent paucicellular lamina propria spindle cell proliferation associated with a sporadic-type intramucosal lipoma $(\times 200)$. (b) Intramucosal lipoma with a more typical subtle spindle cell proliferation infiltrating the lamina propria from a Cowden syndrome intramucosal lipoma $(\times 200)$.

categories of intramucosal lipoma (Table 2). The spindle cells did, however, serve to make the intramucosal lipomas stand out more by H\&E review. Finally, the spindle proliferations were not seen in pseudolipomatosis or submucosal lipomas, as another very useful distinguishing feature.

Table 2 summarizes and compares the histologic, germline genetic, and other phenotypic clinical features across both sporadic-type and Cowden syndromic intramucosal lipoma patients in this series. In summary, there were no pathologic features that distinguished sporadic and Cowden syndromic intramucosal lipomas. Rather, this distinction was accomplished through PTEN germline genetic testing and careful evaluation by trained geneticists for the other phenotypic manifestations of Cowden syndrome.

\section{Pseudolipomatosis and Submucosal Lipoma Controls}

Of the controls, none of the 40 submucosal lipomas extended (Figure 2b) into the mucosa and none of these patients had evidence of Cowden syndrome on chart review. Thus, intramucosal lesions were never seen to arise from extension of a submucosal lesion into the mucosa. Thus, submucosal and intramucosal lipomas appear to be distinct and unrelated lesions (Figures 2a and b). One serrated sessile polyp with an accompanying submucosal lipoma was included in the submucosal lipoma control group. It behaved as all of the other submucosal lesions by not crossing the muscularis mucosae into the mucosa. Spindle cell proliferations were not seen in association with the submucosal lipoma controls.

Of the 30 pseudolipomatosis controls, most $(80 \%)$ occurred directly within mucosa-associated lymphoid tissue and characteristically (92\%) showed small $(10-50 \mu \mathrm{m})$ and irregular gas bubble holes (Figures 2c and d). These were morphologically distinct from the majority macrovesicular and regular fat vacuoles within the lamina propria and adjacent to and surrounding colonic crypts as occurred in true intramucosal lipomas (Figure 2a). The eosinophilic benign lamina propria spindle cell proliferation seen in $80 \%$ of intramucosal lipomas (Figures 3a and b) was not observed in any case of pseudolipomatosis.

\section{Other Colonic Polyps}

In addition, the five definitive Cowden syndrome patients had multiple other hamartomatous and typical colonic polyps, including inflammatory polyps in all five patients (the most common type of polyp in Cowden patients ${ }^{4}$ ), ganglioneuromas in three, lymphoid polyps in three, adenomas in three, hyperplastic polyps in three, and a serrated sessile polyp in one patient. All five Cowden patients had multiple polyp types including hamartomatous polyps, as is highly characteristic of this polyposis syndrome and serves as another important diagnostic clue regarding Cowden syndrome. ${ }^{4}$ The additional polyps present across all 25 intramucosal lipoma patients, inclusive of syndromic and sporadic lesions, are detailed in Table 2.

\section{S-100 Immunohistochemistry}

All the 25 intramucosal and 40 submucosal lipomas stained positively for S-100. The positive S-100 staining was very subtle and delicate and required high power magnification microscopy to detect the delicate membranous S-100-positive rings at the perimeter of the cytoplasmic fat vacuole. The 


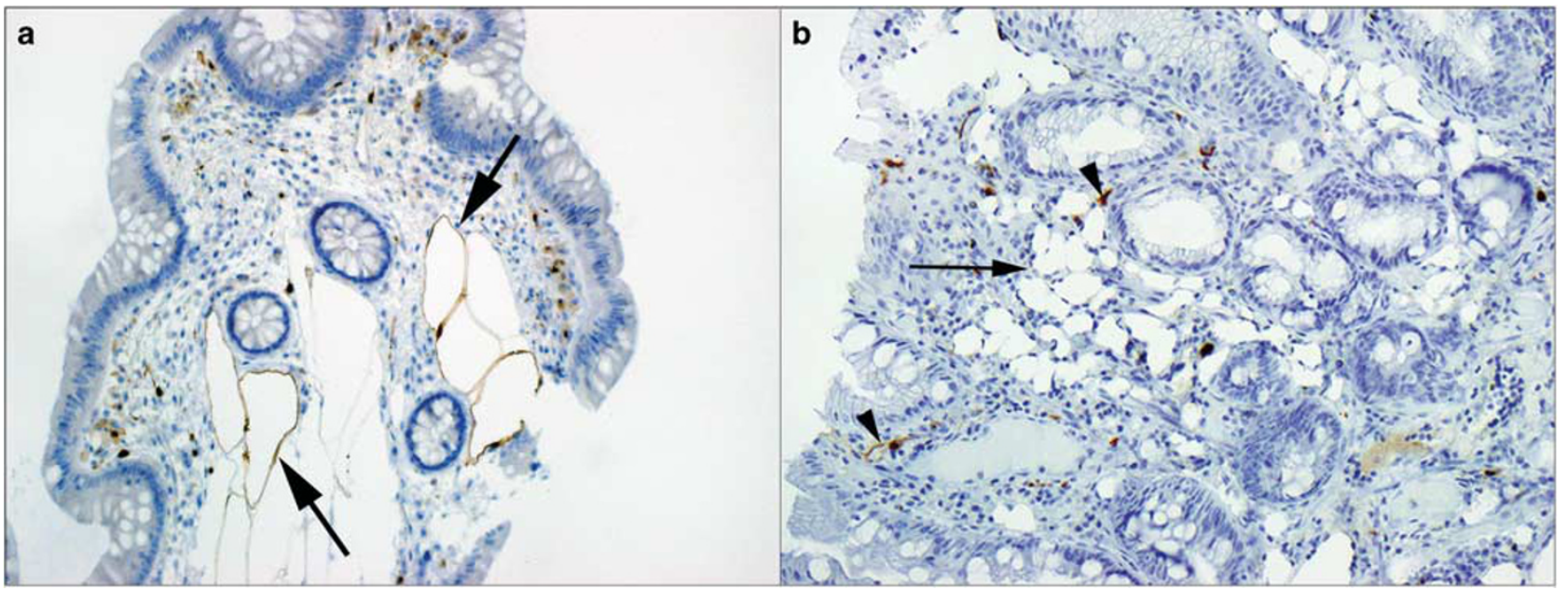

Figure 4 S-100 immunostaining. (a) Intramucosal lipoma ( $\times 400)$, S-100 delicately highlights the adipocyte outer membrane (arrows) and occasionally a nucleus within plane of section. (b) Pseudolipomatosis coli ( $\times 400)$, S-100 does not highlight the insufflation artifact (arrow), but rather stains only lamina propria dendritic cells (arrowheads) for which care should be taken not to over interpret as a false-positive S-100 staining in pseudolipomatosis.

positively staining rings were faint and thin and showed a partial egg-shell pattern (Figure 4a, arrows). Adipocyte nuclear staining was also observed in fortuitous sections exhibiting the small adipocyte nuclei.

Alternatively, the pseudolipomatosis control group demonstrated no S-100 staining on the artifactual gas bubbles (Figure $4 \mathrm{~b}$, arrow). Of note, intramucosal S-100-positive dendritic cells (Figure 4b, arrow heads) can be abundant in normal colonic lamina propria, and if admixed with the gas bubbles of pseudolipomatosis, could lead to the false-positive impression that the negative gas bubbles might be staining. Recognition of the delicate branching dendrites (Figure 4b) of mucosal dendritic cells helps prevent false-positive S-100 interpretation in pseudolipomatosis.

\section{Discussion}

Cowden syndrome (also termed the PTEN hamartoma tumor syndrome) is an inherited autosomal dominant multiple hamartoma syndrome with an increased risk of benign and malignant tumors of the breast, thyroid, endometrium, gastrointestinal tract, and kidney as well as melanoma. Cowden syndrome is included in the spectrum of PTEN hamartoma tumor syndromes. ${ }^{5-7}$

The prevalence of Cowden syndrome is estimated at 1 in 200000 people, but likely remains underdiagnosed due to difficulties inherent in recognizing the great variety of symptoms and signs, which may be subtle and are prevalent in the general population. Moreover, pathognomonic mucocutaneous lesions often go unnoticed. Large recent cohort studies reveal a prevalence of PTEN mutations in $25-35 \%$ of Cowden syndrome patients, ${ }^{7-11}$ indicating that genetic testing, while important, is not helpful in establishing the diagnosis in the great majority of patients. Clinical phenotypic diagnosis, therefore, remains essential in this disease but is challenging. ${ }^{9}$ Consensus clinical diagnostic criteria have been established as the mainstay of diagnosis in Cowden syndrome and consist of a complex combination of major and/or minor criteria (Table 1). ${ }^{9}$

Patients with Cowden syndrome have a markedly increased neoplastic risk, the reason that diagnosis is so important for affected patients and their families. Approximately $55-90 \%$ of patients with Cowden syndrome have an affected parent or sibling, further implicating the importance of diagnosing this highrisk inherited cancer syndrome. ${ }^{11}$ While specific risk estimates have varied, estimates of lifetime breast cancer risk have typically ranged from 25 to $50 \%$, with an average age of diagnosis between 38 and 50 years. Some analyses have reported up to an $85 \%$ breast cancer risk. ${ }^{11}$ Other cancer risks include a 10 to $35 \%$ risk of thyroid cancer, up to a $35 \%$ risk for renal cell carcinoma, $28 \%$ for endometrial cancer, and $9 \%$ colorectal cancer. ${ }^{11}$ Many series report lower rates. ${ }^{9}$

Approximately $90 \%$ of Cowden syndrome patients have colonic polyps and $70 \%$ of patients have more than 50 polyps, qualifying it as a polyposis syndrome. $^{4,12}$ Inflammatory or juvenile-type polyps are the most common polyp type (95\% of patients), ${ }^{4,12}$ and these demonstrate the typical expanded and inflamed lamina propria with crypt architectural distortion. Admixtures of lymphoid polyps ( $63 \%$ of patients), ganglioneuromas (53\% of patients), adenomas (53\% of patients), and hyperplastic polyps (32\% of patients) also occur. ${ }^{4}$ Intramucosal lipomas were present in up to $25 \%$ of Cowden syndrome patients in the largest available series. ${ }^{4}$ An admixture of multiple typical colonic polyp types (adenomas and hyperplastic polyps) in combination with hamartomatous polyps is highly 
characteristic of Cowden syndrome and is a major clue to the diagnosis, described in $54-79 \%$ of Cowden patients., ${ }^{43,14}$ When compared to juvenile polyposis syndrome, Peutz-Jegher syndrome, and nonsyndromic hamartomatous polyposes, intramucosal lipomas have only described in Cowden syndrome. ${ }^{4,13}$

This series of 25 rare intramucosal lipomas revealed five patients $(20 \%)$ with the important inherited multicancer disorder of Cowden syndrome. In four of these, it was the gastrointestinal pathologists' diagnosis of intramucosal lipoma with commentary about the possibility of Cowden syndrome that first lead to the diagnosis. Three patients $(12 \%)$ had additional features for Cowden syndrome but did not meet full clinical diagnostic criteria, and 17 patients $(68 \%)$ were found to have incidental or sporadic intramucosal lipomas without clinical or genetic features. Identification of an intramucosal lipoma in the context of other hamartomatous polyps or a major criterion cancer (breast, follicular thyroid, endometrial) is highly suggestive of Cowden syndrome. However, clinical information regarding many features of Cowden syndrome will not be readily available at the time of polyp pathology review and genetic counseling referral for further assessment can help determine if PTEN gene testing or enhanced cancer screening are needed. Intramucosal lipomas are therefore an important hallmark feature of possible Cowden syndrome for which gastrointestinal pathologists should be aware.

Pseudolipomatosis, ${ }^{2,3}$ or gas bubble infiltration from colonoscopic luminal insufflation, can mimic true intramucosal lipomas. Clues that clear vacuoles resembling fat in the mucosa actually represent artifactual gas bubbles are their variable and generally small to tiny size and their common association with mucosal-associated lymphoid tissue. True lipomas tend to have relatively large or macrovesicular fat vacuoles and more uniform vacuoles that are usually located at the base of the lamina propria. Overlap exists, however, so that it is fortunate that S-100 staining offers an additional means to distinguish these mimics. Given the serious consequences of the diagnosis of a true intramucosal lipoma, confirmatory and simple S-100 staining is highly useful. The S-100 staining pattern of true adipocytes, however, is very delicate, ringing around the cytoplasmic fat vacuoles in a thin, partial egg shelltype pattern. Adipocyte nuclei are also positive, but because they are so small, they are frequently out of the plane of section of the S-100 stain. Pathologists are therefore cautioned to examine S-100 staining of possible intramucosal lipomas under high magnification before excluding this subtle staining pattern. The other caveat with S-100 staining is that normal and often abundant lamina propria dentritic cells stain strongly for S-100. If admixed with the gas bubbles of pseudolipomatosis, dendritic cell positivity can lead to false-positive interpretation of the gas bubbles. Recognition of the branching dendrites of the dentritic cells helps prevent false-positive interpretation.

Some degree of lamina propria spindle cell proliferation was seen in $80 \%$ of intramucosal lipoma cases, while none of the submucosal lipomas or pseudolipomatosis controls revealed this feature. This spindle cell change was present in sporadic and Cowden syndromic intramucosal lipomas alike, so was not helpful in this differential. It did however serve to make the intramucosal lipoma more obvious on H\&E morphology and to exclude the pseudolipomatosis mimics.

From this study, intramucosal lipomas appear also to exist incidentally or sporadically, unrelated to Cowden syndrome, occurring in about two-thirds of patients in this series. The true prevalence of intramucosal lipomas is almost certainly underrecognized by this study, as these lesions are relatively small and unimpressive morphologically and are easily overlooked by gastrointestinal pathologists or dismissed as pseudolipomatosis. Intramucosal adipose pathology has not previously been of much interest or clinical significance, and this combined with its unimpressive appearance microscopically, leads the authors of this study to the strong suspicion that they have been commonly overlooked in the past. Thus, overlooked cases would not have been included in this study, which by necessity was based on a search of diagnosed archival lipomas. The true prevalence of this colonic polyp remains unknown, but it is certainly possible that the two-thirds prevalence of sporadic intramucosal lipomas reported in this series is an underestimate. Nonetheless, the strong association with Cowden syndrome in this series indicates its potential importance as a diagnostic finding.

In conclusion, this series further demonstrates that the intramucosal lipomas are an important diagnostic feature of Cowden syndrome. Proper pathologic and clinical genetic diagnosis of this syndrome, complemented by PTEN germline testing, enables improved cancer prevention through targeted cancer surveillance for these patients and their families. Intramucosal lipomas are subtle and easily missed lesions that gastrointestinal pathologist have not routinely and specifically sought diagnostically. They are mimicked by pseudolipomatosis, but can be recognized readily by pathologists through heightened awareness that fat is never normal within the mucosa and stains positively by S-100, in comparison with pseudolipomatosis gas bubbles which do not. The described morphologic features are also highly useful, including the large and regular size of the fat vacuoles, the lack of involvement of mucosal lymphoid tissue, and the associated benign lamina propria spindle cell proliferations. Increased awareness of this lesion by gastrointestinal pathologists, gastroenterologists, and geneticists should improve the diagnosis of the important and enigmatic condition of Cowden syndrome. 


\section{Acknowledgments}

This study was conducted with support from the Genetic Counseling and the Biorepository and Molecular Pathology Shared Resources supported by the Cancer Center Support Grant awarded to the Huntsman Cancer Institute by the National Cancer Institute of the National Institutes of Health.

\section{Disclosure/conflict of interest}

The authors declare no conflict of interest.

\section{References}

1 Nallamothu G, Adler DG. Large colonic lipomas. Gastroenterol Hepatol (NY) 2011;7:490-492.

2 Wang JH, Furlan A, Kaya D, et al. Pneumatosis intestinalis versus pseudo-pneumatosis: review of CT findings and differentiation. Insights Imaging 2011;2: 85-92.

3 Heng YL, Schuffler MD, Haggitt RC, et al. Pneumatosis intestinalis: a review. Am J Gastroenterol 1995;90: 1747-1758.

4 Shaco-Levy R, Jasperson KW, Martin K, et al. Morphologic characterization of hamartomatous gastrointestinal polyps in Cowden syndrome, Peutz-Jeghers syndrome, and juvenile polyposis syndrome. Hum Pathol 2016;49:39-48.

5 Gammon A, Jasperson K, Kohlmann W, et al. Hamartomatous polyposis syndromes. Best Pract Res Clin Gastroenterol 2009;23:219-231.
6 Lachlan KL, Lucassen AM, Bunyan D, et al. Cowden syndrome and Bannayan-Riley-Ruvalcaba syndrome represent one condition with variable expression and age-related penetrance: results of a clinical study of PTEN mutation carriers. J Med Genet 2007;44: 579-585.

7 Pilarski R, Stephens JA, Noss R, et al. Predicting PTEN mutations: an evaluation of Cowden syndrome and Bannayan-Riley-Ruvalcaba syndrome clinical features. J Med Genet 2011;48:505-512.

8 Tan MH, Mester J, Peterson C, et al. A clinical scoring system for selection of patients for PTEN mutation testing is proposed on the basis of a prospective study of 3042 probands. Am J Hum Genet 2011;88: 42-56.

9 Pilarski R, Burt R, Kohlman W, et al. Cowden syndrome and the PTEN hamartoma tumor syndrome: Systematic review and revised diagnostic criteria. J Natl Cancer Inst 2013;105:1607-1616.

10 Ngeow J, Eng C. Germline PTEN mutation analysis for PTEN hamartoma tumor syndrome. Methods Mol Biol 2016;1388:63-73.

11 Ngeow J, Sesock K, Eng C. Clinical implications for germline PTEN spectrum disorders. Endocrinol Metab Clin N Am 2017;46:503-517.

12 Stanich VL, Owens SS, Khambatta S, et al. Colonic polyposis and neoplasia in Cowden syndrome. Mayo Clinic Proc 2011;86:489-492.

13 Shaco-Levy R, Jasperson KW, Martin K, et al. Gastrointestinal polyposis in Cowden syndrome. J Clin Gastroenterol 2017;51:e60-e67.

14 Stanich PP, Pilarski R, Rock J, et al. Colonic manifestations of PTEN hamartoma tumor syndrome: case series and systematic review. World J Gastroenterol 2014;20: 1833-1838. 